Wright State University

CORE Scholar

1994

\title{
Hopping Conduction in Molecular Beam Epitaxial GaAs Grown at Very Low Temperatures
}

David C. Look

Wright State University - Main Campus, david.look@wright.edu

Z-Q. Fang

J. W. Look

J. R. Sizelove

Follow this and additional works at: https://corescholar.libraries.wright.edu/physics

Part of the Physics Commons

\section{Repository Citation}

Look, D. C., Fang, Z., Look, J. W., \& Sizelove, J. R. (1994). Hopping Conduction in Molecular Beam Epitaxial GaAs Grown at Very Low Temperatures. Journal of The Electrochemical Society, 141 (3), 747-750.

https://corescholar.libraries.wright.edu/physics/658

This Article is brought to you for free and open access by the Physics at CORE Scholar. It has been accepted for inclusion in Physics Faculty Publications by an authorized administrator of CORE Scholar. For more information, please contact library-corescholar@wright.edu. 


\section{Hopping Conduction in Molecular Beam Epitaxial GaAs Grown at Very Low Temperatures}

D. C. Look, Z. -Q. Fang, J. W. Look and J. R. Sizelove

J. Electrochem. Soc. 1994, Volume 141, Issue 3, Pages 747-750. doi: 10.1149/1.2054804

Email alerting Receive free email alerts when new articles cite this article - sign up service in the box at the top right corner of the article or click here

To subscribe to Journal of The Electrochemical Society go to: http://jes.ecsdl.org/subscriptions

(C) 1994 ECS - The Electrochemical Society 


\title{
Hopping Conduction in Molecular Beam Epitaxial GaAs Grown at Very Low Temperatures
}

\author{
D. C. Look, Z-Q. Fang, and J. W. Look \\ University Research Center, Wright State University, Dayton, Ohio 45435
}

\section{J. R. Sizelove}

Solid State Electronics Directorate, Wright Laboratory, Wright-Patterson Air Force Base, Ohio 45433

\section{ABSTRACT}

Conductivity and Hall effect measurements have been performed on $2 \mu \mathrm{m}$ thick molecular beam epitaxial GaAs layers grown at very low substrate temperatures, 200 to $400^{\circ} \mathrm{C}$. For growth temperatures below $300^{\circ} \mathrm{C}$, the conduction is dominated by hopping between arsenic antisite defects of concentrations up to $10^{20} \mathrm{~cm}^{-3}$. Below measurement temperatures of about $130 \mathrm{~K}$, the hopping conduction can be quenched by strong IR light illumination, because the antisite then becomes metastable. The antisite has a thermal activation energy of $0.65 \pm 0.01 \mathrm{eV}$, and thus is not identical to the famous EL2. Both nearest-neighbor and variable-range hopping mechanisms are considered in the analysis.

Early efforts ${ }^{1}$ in the development of molecular beam epitaxial (MBE) growth of GaAs concentrated on reducing impurities and defects to their lowest possible levels. The results over the years were excellent in that shallow level (mostly impurity) background concentrations were reduced to the mid $-10^{13} \mathrm{~cm}^{-3}$ range, and deep level concentrations (both impurities and defects), to the $10^{12} \mathrm{~cm}^{-3}$ range. The best conditions for high quality growth were found to include a substrate temperature of about $600^{\circ} \mathrm{C}$, with departures of more than $50^{\circ} \mathrm{C}$ from this norm producing a noticeable degradation of electrical and optical properties. A very few early studies went to temperatures as low as $300^{\circ} \mathrm{C}$ in order to catalogue the increases in deep levels systematically. ${ }^{2,3}$ Only one paper, as far as we know, suggested that low temperature (LT) growth could produce material useful for any kind of devices. ${ }^{4}$ However, this situation changed in 1988 when Smifh, Calawa, and co-work$\mathrm{ers}^{5}$ showed that $200^{\circ} \mathrm{C} \mathrm{MBE}$ GaAs was very useful as a buffer layer in GaAs metal/semiconductor field effect transistors, and later investigations have provided many more applications. ${ }^{6}$ The most outstanding property of $200^{\circ} \mathrm{C}$ material, as compared to $600^{\circ} \mathrm{C}$ material, is a very high concentration of deep-level defects, in fact about $10^{20} \mathrm{~cm}^{-3}$ arsenic-antisite $\left(\mathrm{As}_{\mathrm{Ga}}\right)$ centers. ${ }^{7}$ The $\mathrm{As}_{\mathrm{Ga}}$ centers are donors, but there are also about $10^{19} \mathrm{~cm}^{-3}$ acceptors, probably gallium vacancy $\left(V_{\mathrm{Ga}}\right)$ related. ${ }^{7}$ For intermediate growth temperatures, say $400^{\circ} \mathrm{C}$, the concentrations of donors and acceptors are about $10^{17} \mathrm{~cm}^{-3}$ and $10^{16} \mathrm{~cm}^{-3}$, respectively. These latter concentrations are closer to those typically found in semi-insulating (SI) liquid-encapsulated Czochralski (LEC) wafers, about $10^{16} \mathrm{~cm}^{-3}$ and $10^{15} \mathrm{~cm}^{-3}$, respectively. Thus, $400^{\circ} \mathrm{C} \mathrm{MBE} \mathrm{GaAs} \mathrm{should} \mathrm{have} \mathrm{electrical}$ properties very similar to those of SI LEC GaAs, and this is indeed the case. For example, note in Fig. 1 the long, straight line Arrhenius plot of $\ln (\mathrm{I}) v s . T^{-1}$ for the $400^{\circ} \mathrm{C}$ sample, where $I \propto \mu n$, and $n$ is given by

$$
n=C_{\mathrm{b}} T^{3 / 2}\left(N_{\mathrm{D}} / N_{\mathrm{A}}-1\right) e^{-E_{\mathrm{D}} / k T}
$$

Here $N_{\mathrm{D}}$ and $N_{\mathrm{A}}$ are the donor and acceptor concentrations, respectively, $C_{\mathrm{b}}$ is a constant, and $E_{\mathrm{D} 0}$ is the donor activation energy at $T=0$. Thus, the 400 and $350^{\circ} \mathrm{C}$ layers are well understood.

Note, on the other hand, the much different low $\mathrm{T}$ behavior of the samples grown at 250 and $300^{\circ} \mathrm{C}$. Clearly, the conduction model is different, and the shallow slopes, along with the known high donor concentrations, suggest hopping conduction. ${ }^{9}$ However, there is a strong difference between this hopping conduction and that studied in great detail in the past, ${ }^{10,11}$ because in this case the hops are between deep centers with tightly bound wave functions, whereas in the earlier investigations they were between shallow centers with extended (hydrogenic) wave func- tions. Nevertheless, the classical hopping model seems to do quite well in explaining most of the observed features. (Exceptions will be discussed later.)

\section{Hopping Model and Applications}

The samples used in this study were grown in a Varian Gen II MBE system using an $\mathrm{As}_{4} / \mathrm{Ga}$ beam equivalent pressure ratio of about 20 . Temperatures were measured with a thermocouple placed near to, but not touching, the substrate. For growth temperature $T_{\mathrm{G}}=400^{\circ} \mathrm{C}$, the thermocouple could be calibrated with an optical pyrometer; however, no such calibration was possible at lower temperatures so that absolute accuracy could not be established for $T_{G}<$ $400^{\circ} \mathrm{C}$. Layer thicknesses were $5 \mu \mathrm{m}$ for the 300 and $400^{\circ} \mathrm{C}$ samples, and $2 \mu \mathrm{m}$ for the 200 and $250^{\circ} \mathrm{C}$ samples. All layers were single crystal. Annealing at each temperature $T_{\mathrm{A}}$ was carried out for $10 \mathrm{~min}$ in a furnace under flowing Ar gas.

Consider the curve designated " $T_{\mathrm{G}}=300^{\circ} \mathrm{C}$ " in Fig. 1 . It is clear that the conduction at measurement temperatures $T>$ $340 \mathrm{~K}$ (or $1000 / T<2.9$ ) is activated, with an activation

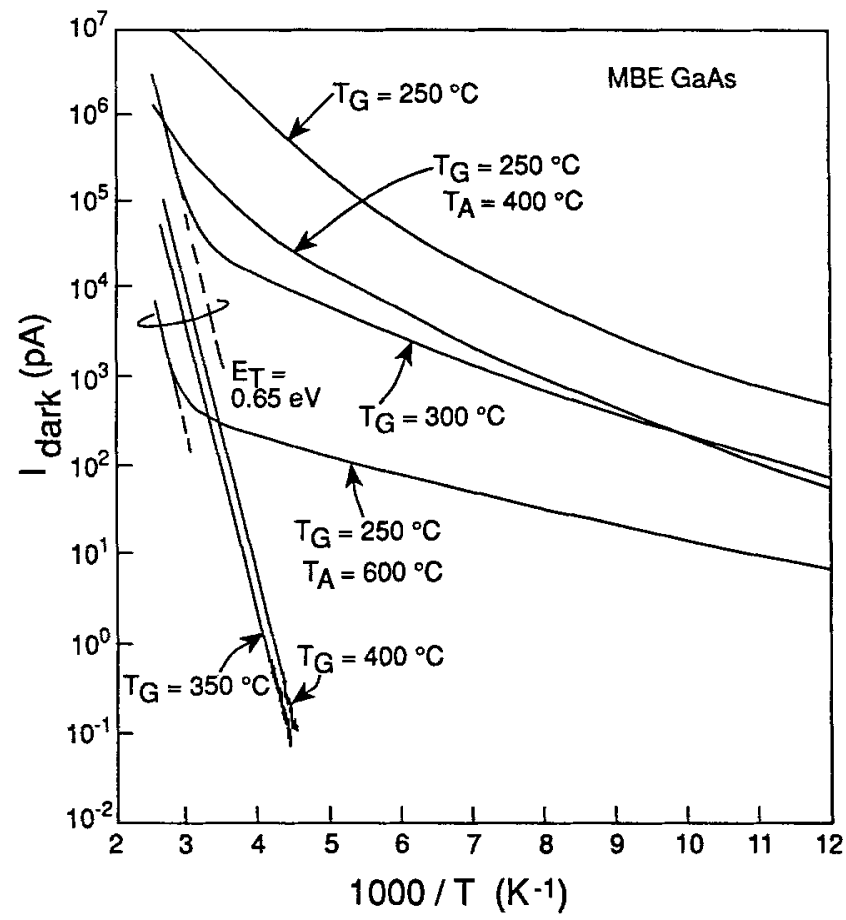

Fig. 1. Dark current (20 V bias) vs. $T^{-1}$ for MBE GaAs samples grown af various temperatures. " $T_{G}$ " denotes growth temperature, and " $T_{A}$ " annealing temperature. 


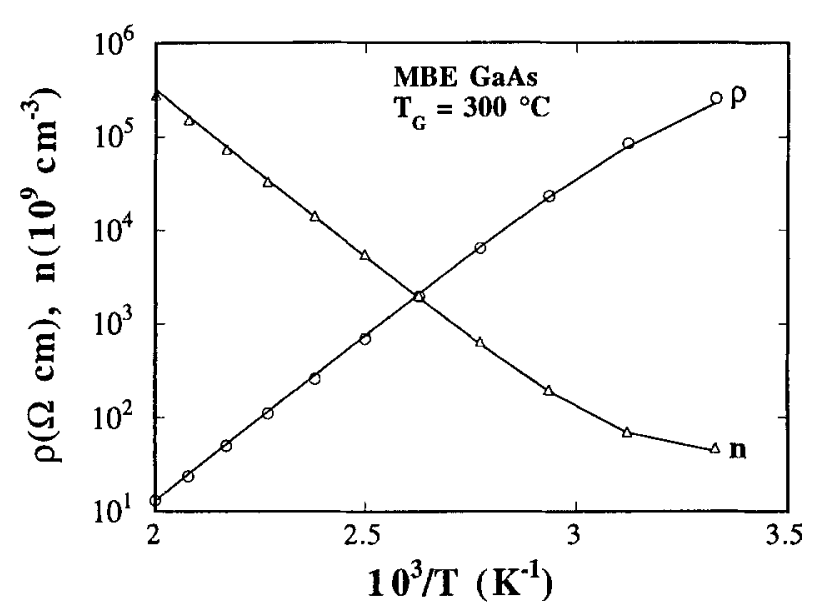

Fig. 2. The measured resistivity $\rho$ and carrier concentration $\boldsymbol{n}$ (actually $1 / e R$ ) vs. $T^{-1}$ for an $\mathrm{MBE}$ GaAs sample grown at $300^{\circ} \mathrm{C}$. The solid lines are theoretical fits.

energy $E_{\mathrm{D} 0} \simeq 0.65 \mathrm{eV}$. The same value of $E_{\mathrm{D} 0}$ is seen over the whole temperature range for the samples grown at 350 and $400^{\circ} \mathrm{C}$. However, for the $300^{\circ} \mathrm{C}$ sample the $I$ vs. $T$ (or $n$ vs. $T$ ) slope becomes much shallower below $T=340 \mathrm{~K}$ and hopping conduction is evidently dominant. An even stronger effect is seen for the $250^{\circ} \mathrm{C}$ sample in that there is no region dominated by activated (band) conduction, i.e., even the high-temperature portion seems to have a strong component of hopping conduction. Thus, a general model must include both mechanisms, so that the overall conductivity $\sigma$ and Hall coefficient $R$ should be given by

$$
\begin{gathered}
\sigma=\sigma_{\mathrm{b}}+\sigma_{\mathrm{h}} \\
R=\frac{\sigma_{\mathrm{b}}^{2} R_{\mathrm{b}}+\sigma_{\mathrm{h}}^{2} R_{\mathrm{h}}}{\left(\sigma_{\mathrm{b}}+\sigma_{\mathrm{h}}\right)^{2}}
\end{gathered}
$$

where $\mathrm{b}$ denotes band, and $\mathrm{h}$ denotes hopping conduction. ${ }^{9}$ The band conductivity can be simply written $\sigma_{b}=e n \mu$ where $n$ is given by Eq. 1, and $\mu$ can be written as a function of $N_{\mathrm{A}}$ and lattice parameters in a Matthiessen's rule approximation. ${ }^{12}$ Near room temperature, the hopping conduction is expected to be of the nearest-neighbor variety, ${ }^{10,11}$ described by

$$
\begin{aligned}
\sigma_{\mathrm{h}} & =C_{\mathrm{h}} e^{-\gamma \mathrm{R} / \mathrm{a}} e^{-\varepsilon_{3} / k \mathrm{~T}} \\
& =C_{\mathrm{h}} e^{-1.8 / \mathrm{aN}^{1 / 3}} e^{-\mathrm{bN} N_{\mathrm{D}}^{1 / 3} / \mathrm{kT}}
\end{aligned}
$$

where $\gamma$ and $C_{h}$ are constants derivable only from detailed theory, $a$ is the extent of the donor wavefunction, and $\epsilon_{3}$ is the difference between the isolated donor energy and the Fermi energy. We can estimate $a$ from a hydrogenic model: $a \simeq h /\left(2 m^{*} E_{\mathrm{D} 0}\right)^{1 / 2} \simeq 9.3 \AA$. Thus, if $a N_{\mathrm{D}}^{1 / 3} \ll 1$ (say $a N_{\mathrm{D}}^{1 / 3} \simeq$ 0.01 , or $N_{\mathrm{D}} \leqslant 8 \times 10^{16} \mathrm{~cm}^{-3}$ ) the hopping conduction should be very weak. This contention is borne out in the 350 and $400^{\circ} \mathrm{C}$ samples, for which we know ${ }^{8}$ that $N_{\mathrm{D}} \simeq 10^{17} \mathrm{~cm}^{-3}$, and indeed, $\sigma_{\mathrm{h}}$ is negligible.

Shklovskii ${ }^{11}$ has shown that $b \simeq C_{1} e^{2} / 4 \pi k$ (MKS units), where $\kappa$ is the dielectric constant and $C_{1} \simeq 0.99$ for low compensation and randomly placed acceptors. If, in fact, the acceptors tend to be closer to the donors because of coulombic attraction, then it seems plausible that $C_{1}$ should be somewhat higher. Shklovskii has also argued that $C_{h}$ should be of the same order of magnitude as the "band conductivity of $N_{\mathrm{D}}$ electrons," which would evidently be about $e N_{\mathrm{D}} \mu$. We can check these concepts by fitting the $300^{\circ} \mathrm{C}$ growth $\sigma$ and $R$ data to Eq. 2 and 3 , where $\sigma_{\mathrm{b}}=n e \mu$, $R_{\mathrm{b}}=1$ /en, $R_{\mathrm{h}}=0$ (cf. Ref. 9), and $\sigma_{\mathrm{h}}$ is given by Eq. 4 . Also, we take $n$ from Eq. 1 and $\mu$ from Eq. 3 of Ref. 12. The fit is excellent as shown in Fig. 2, with the following fitting parameters: if $C_{\mathrm{b}}$ in Eq. 1 is taken as $7.56 \times 10^{15} \mathrm{~cm}^{-3} \mathrm{~T}^{-3 / 2}$ (Ref. 12), then $N_{\mathrm{D}}=3.2 \times 10^{18} \mathrm{~cm}^{-3}, N_{\mathrm{A}}=2.1 \times 10^{17} \mathrm{~cm}^{-3}$ $E_{\mathrm{D} 0}=0.654 \mathrm{eV}, C_{\mathrm{h}} \simeq 410 \Omega^{-1} \mathrm{~cm}^{-1}$, and $C_{1} \simeq 9.1$. The value of $E_{\mathrm{D} 0}$ is very close to what is found for 350 and $400^{\circ} \mathrm{C}$ samples, which have no hopping conduction. Also, we can check $C_{h}$ with the estimated value, $e N_{\mathrm{D}} \mu \simeq e\left(3.2 \times 10^{18}\right)\left(1.7 \times 10^{3}\right) \simeq$ $871 \Omega^{-1} \mathrm{~cm}^{-1}$, which is certainly of the same order of magnitude. However, the quantity of $C_{1}$ seems much too large.

One problem here is in the potential inaccuracy of the fitted parameters. Note in Fig. 3 that even though the hopping conductivity $\sigma_{\mathrm{h}}$ is larger than the band conductivity $\sigma_{\mathrm{b}}$ at $300 \mathrm{~K}$, it is already smaller by $310 \mathrm{~K}$ and has little influence beyond $340 \mathrm{~K}$. Thus, we might expect that the hopping parameters $C_{h}$ and $C_{1}$ may not be too accurate. To obtain error estimates on $C_{\mathrm{h}}$ and $C_{1}$, we can assume a much smaller value for $C_{\mathrm{b}}$ in Eq. 1, $1.85 \times 10^{15} \mathrm{~cm}^{-3} T^{-3 / 2}$, for which there is also some justification. ${ }^{13}$ Then the fitting parameters become: $N_{\mathrm{D}} \simeq 4.0 \times 10^{18} \mathrm{~cm}^{-3}, N_{\mathrm{A}} \simeq 1.1 \times 10^{17} \mathrm{~cm}^{-3}, E_{\mathrm{D} 0} \simeq$ $0.636 \mathrm{eV}, C_{\mathrm{h}} \simeq 4.4 \Omega^{-1} \mathrm{~cm}^{-1}$, and $C_{1} \simeq 3.4$. This fit (not shown in Fig. 2) is somewhat worse, but not unreasonable, so that the combination of each new and old parameter gives a measure of the accuracy in that parameter. Obviously $C_{h}$ and $C_{1}$ tend to trade off, so that neither is known very accurately. However, it still appears that $C_{1}>0.99$, which may suggest that the acceptors are closer to donors, on the average, than a simple random placement would permit.

We can check the $\exp \left(-1.8 / a N_{D}^{1 / 3}\right)$ term in Eq. 4 by comparison with a sample grown at $200^{\circ} \mathrm{C}$ and having $N_{\mathrm{D}} \simeq 8.1$ $\times 10^{19} \mathrm{~cm}^{-3}$, as measured by both the Hall effect and absorption. In the $200^{\circ} \mathrm{C}$ sample the fitted $\sigma_{\mathrm{h}}$ at $300 \mathrm{~K}$ is $3.1 \times$ $10^{-3} \Omega^{-1} \mathrm{~cm}^{-1}$ whereas the value is $2.8 \times 10^{-6}$ in the $300^{\circ} \mathrm{C}$ layer. The ratio of these values is consistent with $a \simeq 11.4 \AA$, which is in good agreement with our "hydrogenic" value of $9.3 \AA$. The $\exp \left(-b N_{\mathrm{D}}^{1 / 3} / k T\right)$ term will, of course, modify our comparison somewhat, but the dependence on $N_{D}$ in this term is much weaker as long as $C_{1}$ is not too much larger than unity.

Below some temperature, the relatively large value of $\epsilon_{3}$ in Eq. 4 makes the nearest-neighbor hopping process weak, and another mechanism, variable-range hopping, takes over. ${ }^{10,11}$ This type of hopping occurs within a subset of the donors, $\Delta N_{\mathrm{D}}$, which are spatially spread out but are all within $\Delta \epsilon$ of the Fermi level. By substituting $\Delta N_{\mathrm{D}}$ for $N_{\mathrm{D}}$ in Eq. 4, and $\Delta \epsilon$ for $\epsilon_{3}$, and using the relationship $\Delta N_{D} \propto \Delta \epsilon$, we can maximize $\sigma_{\mathrm{h}}$ with respect to $\Delta N_{\mathrm{D}}$ and finally get

$$
\sigma_{\mathrm{h}}=C_{\mathrm{h}} e^{-\left(\mathrm{T}_{0} /\right)^{1 / 4}}
$$

The parameter $T_{0}$, in one formulation, ${ }^{14}$ is given by

$$
T_{9} \simeq 76 \frac{w}{k} \alpha^{3} \frac{3}{4 \pi \bar{N}_{\mathrm{D}}}=C_{\mathrm{T}} / N_{\mathrm{D}}
$$

Here $w$ denotes the width of the defect band, $\alpha=\left(m^{*} E_{\mathrm{g}}\right)^{1 / 2} /$ $h$ is a tunneling length, and $k$ is Boltzmann's constant. Other forms of $T_{0}$ have also been suggested, ${ }^{11}$ but it is difficult to define this quantity precisely. In Fig. 4 we plot In $\left(I_{\text {dark }}\right)$ vs. $T^{-1 / 4}$ for several samples, where $T_{G}$ and $T_{\mathrm{A}}$ denote the growth and annealing temperatures, respectively. Note that the $T^{-1 / 4}$ dependence seems to hold fairly well over rather wide temperature ranges. We can fit the 300 to $500 \mathrm{~K}$ data of Fig. 2 by using Eq. 5 for $\sigma_{h}$, instead of Eq. 4, with the following parameters resulting (here we have fixed $C_{\mathrm{b}}=$ $\left.7.56 \times 10^{15} \mathrm{~cm}^{-3} T^{-3 / 2}\right): N_{\mathrm{D}}=3.1 \times 10^{18} \mathrm{~cm}^{-3}, N_{\mathrm{A}}=2.7 \times$

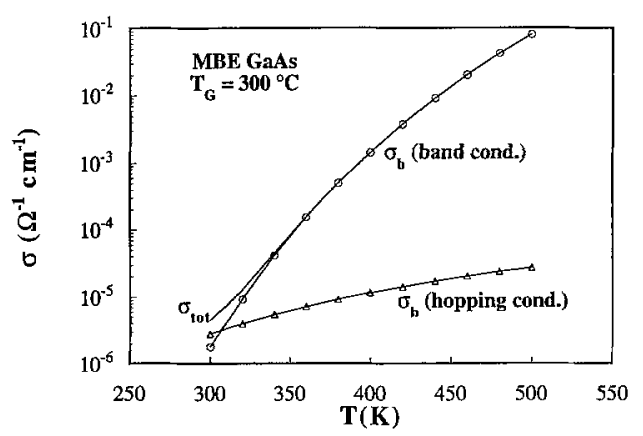

Fig. 3. Hopping conductivity $\sigma_{h}$ and band conductivity $\sigma_{b} v s$. $T^{-1}$ for an MBE GaAs sample grown af $300^{\circ} \mathrm{C}$. The quantities $\sigma_{h}$ and $\sigma_{b}$ are deduced from of fit of Eq. 2 and 3, see text. 


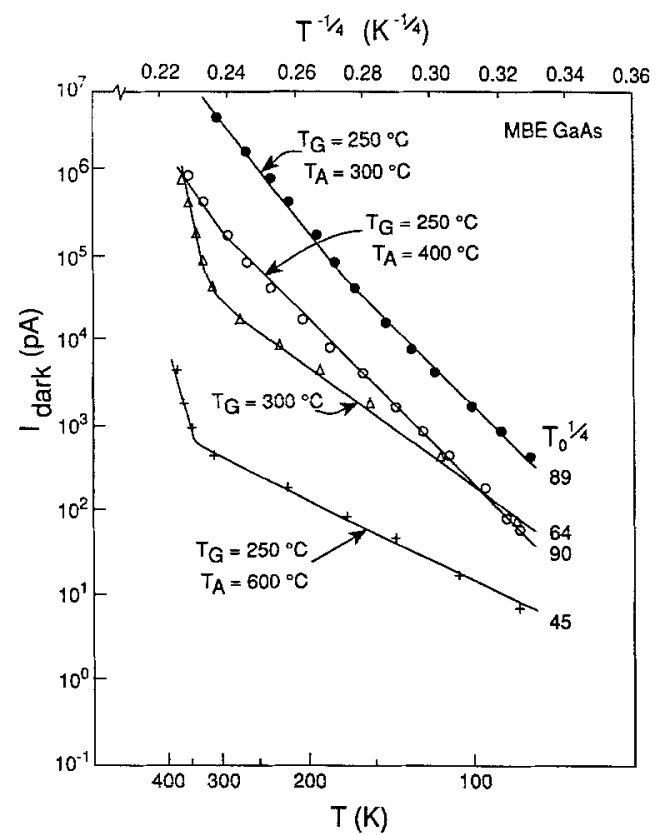

Fig. 4. Dark current vs. $T^{-1 / 4}$ for some of the samples shown in Fig. 1. The parameter $T_{0}^{1 / 4}$ is discussed in the text and appears in Eq. 5.

$10^{17} \mathrm{~cm}^{-3}, E_{\mathrm{D} 0}=0.643 \mathrm{eV}, C_{\mathrm{h}}=167 \Omega^{-1} \mathrm{~cm}^{-1}$, and $C_{\mathrm{T}}=3.14 \times$ $10^{6} \mathrm{~K} / \mathrm{cm}^{3}$. (The fit is as good as that shown in Fig. 2.) Note that $N_{\mathrm{D}}, N_{\mathrm{A}}$, and $E_{\mathrm{D} 0}$ have changed little from the previous values, because they are constrained by the band conduction, which is dominant above $320 \mathrm{~K}$ (Fig. 3). From the values of $C_{\mathrm{T}}$ and $N_{\mathrm{D}}$, we get $T_{0}=3.11 \times 10^{7} \mathrm{~K}$, or $T_{0}^{1 / 4}=$ $75 \mathrm{~K}^{1 / 4}$. This value is less accurate than the $T_{0}^{1 / 4}=64 \mathrm{~K}^{1 / 4}$ derived from the low-temperature data (Fig. 4), because, again, the hopping conduction has little influence in the 300 to $500 \mathrm{~K}$ fit. From Eq. 6 , the value $T_{0}^{1 / 4}=64 \mathrm{~K}^{1 / 4}$ gives $w \simeq 0.16 \mathrm{eV}$, a reasonable value for the width of the defect band. However, it is unclear as to whether variable-range hopping should be stronger than nearest-neighbor hopping at, say, $300 \mathrm{~K}$. This point will be discussed later.

A very interesting phenomenon associated with the hopping conduction takes place when samples are illuminated with IR light at low temperature. ${ }^{15,16}$ In Fig. 5 we show results for a sample which was grown at $200^{\circ} \mathrm{C}$ and then annealed at $550^{\circ} \mathrm{C}$ in a furnace for $10 \mathrm{~min}$, a process which reduces the defect density considerably but still leaves hopping conduction dominant below room temperature. If there is no illumination, the current at $82 \mathrm{~K}$ is about $50 \mathrm{pA}$, but it increases considerably as temperature is raised (at $0.3 \mathrm{~K} / \mathrm{s}$ in this case) because of the temperature dependence of the hopping conduction. A fit according to Eq. 5 is shown

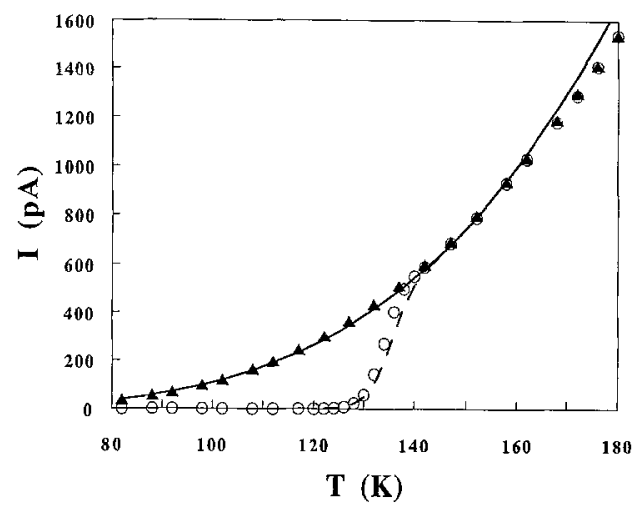

Fig. 5. Dark current vs. $T$ for a sample grown at $250^{\circ} \mathrm{C}$ and annealed at $550^{\circ} \mathrm{C}$, under conditions of no prior illumination (triangles), and prior illumination with $\mathrm{IR}$ light at $82 \mathrm{~K}$ (circles). The solid and dashed lines are theoretical fits. as the solid line in the figure, and it obviously well predicts the behavior from 82 to $160 \mathrm{~K}$, although Eq. 4 (fit not shown) agrees more closely with the data above $160 \mathrm{~K}$. When IR light (8 W tungsten lamp, Si filter, $h v \leqslant 1.12 \mathrm{eV}$, $\sim 10^{16} \mathrm{phot} / \mathrm{cm}^{2} \mathrm{~s}$ ) is shone on the sample for $5 \mathrm{~min}$, the current drops by a factor of 350 (difficult to see in Fig. 5, but $c f$. Ref. 16). Then, raising the temperature produces the circled points, theoretically fitted by the dashed line (again, see Ref. 16 for details). What is happening here is that the IR light "quenches" the hopping conduction by causing a high fraction of the $\mathrm{As}_{\mathrm{Ca}}$ hopping centers to transform to their metastable states (probably due to a positional change). In the metastable state, hopping evidently cannot be sustained, perhaps because the electronic wave function is more tightly bound. Then, as temperature is raised to about $140 \mathrm{~K}$, the metastable $\mathrm{As}_{\mathrm{Ga}}$ centers recover to their ground states and hopping proceeds once more. The fit to the circled points in Fig. 5 gives a recovery rate $r=3$ $\times 10^{8} \exp (-0.26 / k T)$, exactly the same as that of EL2, which is known to be either an isolated or else weakly complexed $\mathrm{As}_{\mathrm{Ga}}$ center. Thus, we have proven that the hopping phenomenon in the LT MBE GaAs layers is due to closely spaced $\mathrm{As}_{\mathrm{Ga}}$ centers.

\section{Discussion}

We have clearly shown that the dominant room-temperature conduction mechanism in MBE GaAs grown at substrate temperatures below $300^{\circ} \mathrm{C}$ is hopping between defects which have an arsenic antisite $\left(\mathrm{As}_{\mathrm{Ga}}\right)$ as the main component. In Table I we compare the measured hopping conductivity with the average donor separation $R_{\mathrm{av}}$ for samples grown at 200,300 , and $400^{\circ} \mathrm{C}$. Naively, we would expect that the hopping probability should depend on the wave function overlap, i.e., $\exp \left(-2 R_{\text {av }} / a\right)$, where $a \simeq 9 \AA$ for a donor of energy $0.65 \mathrm{eV}$ (hydrogenic model). Indeed, the measured hopping conductivities are in good qualitative agreement with this model. Coupled with the IR quenching experiments and the lack of a Hall mobility $\left(R_{\mathrm{h}}=0\right)$ in the hopping regime, ${ }^{9}$ there is no doubt that hopping is taking place. However, there are still some troubling points and unanswered questions.

Suppose we assume that the hopping is of the nearestneighbor variety (Eq. 4) for our 300 to $500 \mathrm{~K}$ fit of the data for the sample grown at $300^{\circ} \mathrm{C}$ (Fig. 2). Then the relevant activation energy in the hopping regime is $\epsilon_{3} \simeq C_{1} e^{2} N_{\mathrm{D}}^{1 / 3} /$ $4 \pi \kappa$, where, according to Shklovskii, ${ }^{11} C_{1}$ should be about 0.99 . However, we get $C_{1} \simeq 3$ to 9 , depending on our choice of $C_{\mathrm{b}}$ in Eq. 1. If the acceptors are not randomly placed but are indeed closer to particular donors than expected (say, due to coulomb attraction during growth), then $C_{1}$ could be larger than 0.99 . This possibility should be explored further.

However, we can also fit the data of Fig. 2 quite well with variable-range hopping (Eq. 5), and get a value for $T_{0}$ of $3.11 \times 10^{7} \mathrm{~K}$. From the low temperature data of the same sample (Fig. 4), we get $T_{0} \simeq(64)^{4} \simeq 1.68 \times 10^{7} \mathrm{~K}$, in satisfactory agreement. But would we really expect variable-range hopping to be stronger than nearest-neighbor hopping at such high temperatures? Shklovskii has suggested a rough criterion for determining the critical temperature $T_{\mathrm{C}}$ above which nearest-neighbor hopping takes over. At low compensation, $N_{\mathrm{A}} / N_{\mathrm{D}} \ll 1, T_{\mathrm{C}}$ is given in his model by

$$
T_{\mathrm{C}}=\frac{e^{2} N_{\mathrm{D}}^{2 / 3} a}{k(4 \pi \kappa)}\left(\frac{N_{\mathrm{A}}}{N_{\mathrm{D}}}\right)^{1 / 3}
$$

which gives $T_{\mathrm{C}} \simeq 116$ and $11 \mathrm{~K}$ for samples grown at 200 and $300^{\circ} \mathrm{C}$, respectively. However, the exp $\left[-\left(T_{0} / T\right)^{1 / 4}\right]$ dependences shown in Fig. 4 appear to hold at much higher temperatures than these $T_{\mathrm{C}} \mathrm{S}$. It is, of course, possible that Eq. 7 represents an unrealistic approximation for $T_{C}$, but, again, further studies need to be carried out.

In summary, it appears that low temperature grown MBE GaAs offers a fruitful laboratory for the study of hopping conduction. Because the energies of the centers promoting the hopping are deep, some of the present theory, ${ }^{10.11}$ which is primarily based on shallow center (effective mass) wave 
Table I. Hopping conductivities at different growth temperatures compared with $\exp \left(-2 R_{\mathrm{av}} / a\right)$, where $R_{\mathrm{av}}=\left(3 / 4 \pi N_{0}\right)^{1 / 3}$ and $a \simeq 9 \AA$ (the extent of the wave function).

\begin{tabular}{|c|c|c|c|c|c|}
\hline $\begin{array}{l}\text { Growth } T \\
\left({ }^{\circ} \mathrm{C}\right)\end{array}$ & $N_{\mathrm{D}}$ & $N_{\mathrm{A}}$ & $\begin{array}{l}R_{\mathrm{av}} \\
(\AA)\end{array}$ & $e^{-2 R_{0} / \mathrm{a}}$ & Meas. $\sigma_{\mathrm{h}}(300 \mathrm{~K})$ \\
\hline $\begin{array}{l}200 \\
300 \\
400\end{array}$ & $\begin{array}{l}8 \times 10^{19} \mathrm{~cm}^{-3} \\
3 \times 10^{18} \mathrm{~cm}^{-3} \\
2 \times 10^{17} \mathrm{~cm}^{-3}\end{array}$ & $\begin{array}{l}1 \times 10^{19} \mathrm{~cm}^{-3} \\
2 \times 10^{17} \mathrm{~cm}^{-3} \\
5 \times 10^{16} \mathrm{~cm}^{-3}\end{array}$ & $\begin{array}{r}14 \\
43 \\
106\end{array}$ & $\begin{array}{l}4 \times 10^{-2} \\
7 \times 10^{-5} \\
3 \times 10^{-11}\end{array}$ & $\begin{array}{c}3 \times 10^{-3} \Omega^{-1} \mathrm{~cm}^{-1} \\
3 \times 10^{-6} \Omega^{-1} \mathrm{~cm}^{-1} \\
<10^{-11} \Omega^{-1} \mathrm{~cm}^{-1}\end{array}$ \\
\hline
\end{tabular}

functions, may have to be revised. It is hoped that further studies, both experimental and theoretical, will be successful in solving some of the outstanding problems.

\section{Acknowledgments}

We would like to thank E. N. Taylor, J. E. Ehret, and C. E. Stutz for growing the MBE layers discussed in this paper, T. A. Cooper for electrical measurements, G.D. Robinson for layer removal, L. Callahan for sample preparation, and R. Heil for preparing the manuscript. D.C.L. was supported under U.S. Air Force Contract F33615-91-C-1765, Z-Q.F. under ONR Contract N00014-90-J-11847, and J.W.L. under a Nippon Mining Company grant.

Manuscript submitted May 28, 1993; revised manuscript submitted Nov. 2, 1993

Wright State University assisted in meeting the publication costs of this article.

\section{REFERENCES}

1. An excellent review of MBE studies up through 1988 is given by $\mathrm{H}$. Sakaki, in $I I T-V$ Semiconductor Materials and Devices, R. J. Malik, Editor, Chap. 5, North-Holland, Amsterdam (1989).

2. C. E. C. Wood, J. Woodcock, and J. J. Harris, Inst. Phys. Conf. Ser, 45, 28 (1979).

3. R. A. Stall, C. E. C. Wood, P. D. Kirchner, and L. F.
Eastman, Electron. Lett., 16, 171 (1980)

4. T. Murotani, T. Shimanoe, and S. Mitsui, J. Crystal Growth, 45, 302 (1978).

5. F. W. Smith, A. R. Calawa, C.-L. Chen, M. J. Manfra, and L. J. Mahoney, IEEE Electron Device Lett., EDL9, 77 (1988)

6. Mat. Res. Soc. Symp. Proc., 241 (1992).

7. D. C. Look, D. C. Walters, M. Mier, C. E. Stutz, and S. K. Brierley, Appl. Phys. Lett., 60, 2900 (1992).

8. D. C. Look, G. D. Robinson, J. R. Sizelove, and C. E. Stutz, ibid., 62, 3004 (1993).

9. D. C. Look, D. C. Walters, M. O. Manasreh, J. R. Sizelove, C. E. Stutz, and K. R. Evans, Phys. Rev. B, 42, 3578 (1990).

10. N. F. Mott and W. D. Twose, Adv. Phys., 10, 107 (1961).

11. B. I. Shklovskii, Sov. Phys. Semicond., 6, 1053 (1973) [Fiz. Tekh. Poluprovodn., 6, 1197 (1972)].

12. D. C. Look, D. C. Walters, G. D. Robinson, J. R. Sizelove, M. G. Mier, and C. E. Stutz, J. Appl. Phys., 74, 306 (1993).

13. J. S. Blakemore, in Semi-Insulating III-V Materials, Hakone, 1986, H. Kukimoto and S. Miyazawa, Editors, p. 389, Ohmsha, Tokyo (1986).

14. K. Kuriyama, Y. Yokayama, and K. Taniguchi, Phys. Rev. B, 45, 6251 (1992).

15. Z-Q. Fang and D. C. Look, Appl. Phys. Lett., 61, 1438 (1992).

16. D. C. Look, Z-Q. Fang, and J. R. Sizelove, Phys. Rev. B, 47, 1441 (1993).

\title{
Insight into Gate Oxide Thinning
}

\author{
P. Bellutti and A. Lui \\ IRST-Istituto per la Ricerca Scientifica e Tecnologica, Material Science/Microelectronics Division, \\ 38050 Provo-Trento, Italy
}

\section{ABSTRACT}

Gate oxide thinning, induced by local selective oxidation, has been studied by using scanning electron microscopy to evaluate the bird's beak cross sections in $n$ - and $p$-type silicon. Distinct characteristics of the thinned regions show a clear dependence of the gate oxide thinning on both substrate doping concentration and type. The influence of both pad and field oxide thicknesses as well as process temperature have been analyzed.

Selective local oxidation of silicon (LOCOS) is the conventional way for lateral electrical isolation of very large scale integrated (VLSI) devices. It consists of the growth of thick oxide (referred to as field oxide) by using wet oxidation of the substrate, selectively covered with an oxidation mask. The field oxide growth implicates some problems that must be controlled to avoid degradation of device performance and yield reduction. These problems are mainly related to the use of silicon nitride as masking material. Silicon nitride is an extremely good barrier to the diffusion of oxidizing agents, but its different thermal expansion coefficient compared with silicon induces a stress which can promote defects. A pad oxide is usually grown before nitride deposition to reduce the stress and, to this purpose, the thicknesses of both oxide and nitride films must be chosen carefully. The oxidizing agents can diffuse under the nitride edge through the pad oxide, thus giving rise to the sideways encroachment of the isolation field oxide (the so-called bird's beak formation).
Among the problems induced by LOCOS, of particular relevance is the gate oxide thinning, an anomaly in gate oxide growth which has a severe impact on yield as well as on reliability of devices and it is still present in the modified LOCOS process, e.g., PBLOCOS,${ }^{1}$ available for submicron technology. It has been reported that the appearance of gate oxide thinning is related to the decomposition process of the nitride layer used for masking the active regions during wet field oxidation. ${ }^{2,3}$ In particular it has been proposed that the nitride decomposition, promoted by the wet oxidizing atmosphere, produced $\mathrm{NH}_{3}$ (or similar type of chemical species) which reacts at the $\mathrm{Si} / \mathrm{SiO}_{2}$ interace forming a silicon nitride or oxynitride layer. Since the nitridation reaction is self-limiting, this layer is limited in a very thin region which cannot be seen by direct analysis. The effects related to its presence are strong, as is well demonstrated by the oxide thinning, which develops during the following gate oxide growth, due to a local temporary inhibition of the oxidation process. In most cases, the thinned region appears to be symmetrically distributed 